\author{
Suitability of conductive knit fabric for sensing human breathing \\ Aliaa A. Mohamed ${ }^{*}$, Mohamed M. Ezzat ${ }^{2}$, Z. M. Abdel Megeid ${ }^{2}$, Ahmed Saeed $^{3}$ \\ ${ }^{1}$ Faculty of Women Ain Shams University, Textile and Clothing, Cairo, Egypt \\ ${ }^{2}$ National Research Center, Textile Research Division, Dokki, Cairo, Egypt \\ ${ }^{3}$ Electronics, Communications and Computer engineering, Helwan University, Cairo, Egypt
}

\begin{abstract}
:
This paper studies the suitability of conductive knit fabric in order to produce a reliable breathing sensor. Conductive single jersey knit fabrics was manufactured from silver coated nylon yarn with different production parameters (stitch type (ST)- combination ratio (CR) and number of wales (NW)). A cyclic tester was built to simulate the breathing mechanism of a human being and to explore the influence of these parameters on the electric resistance. The results show that there is a significant effect on the resistance value by the difference in ST and CR, while the width of the sample doesn't show a significant effect.The best sample suited for breathing sensor is the one with increase in width (NW), less CR and normal stitch.
\end{abstract}

Key words: conductive fabric- breathing sensor- combination ratio -stitch type.

\title{
1. Introduction:
}

Conductive yarn when integrated or embedded in a textile fabric it possesses some electric properties to the fabric. This fabric can be used in different application including textile pressure sensor(Coyle, et al., 2010) (Meyer, etal., 2010) (Rothmaier, et al., 2008), anti-electrostatic textiles (Cheng, Ueng, \& Dixon, 2001), electromagnetic shielding sensor (Ceken, et al., 2012)(Perumalraj \& Narayanan, 2014)and breathing sensor.

Noury et al measured the respiration frequency by using an inductive sensor formed in sinusoidal pattern. (Noury, et al., 2004). Merrit and Paradiso et al, produced a piezoresistive breathing sensor by using carbon-loaded rubber (Paradiso, et al,. 2005), (Merrrit, 2008).

While,Zieba and Frydrysiaskstudied the electric resistance of knitting as well as weaving textiles integrated with conductive yarn. They stated that conductive polymer yarn and optical fibers can be useful in designing breathing senor(Zięba \& Frydrysiak, 2006).Moreover, a textile digital sensor named"E-vital wear" was developed.This device was applied for measuring the human physiological signal including respiration monitoring(Yang, et al., 2008).

Many authors tend to explore the influence of conductive knitting fabric production parameters on electric and mechanical properties(Li L. , et al., 2009),(Li, Liwen et al., 2009)(Guo, et al., 2013)(Ehrmann, et al., 2010)(Qureshi, et al., 2011) (Atalay , et al., 2013)(Atalay, et al, 2015)(Liu , et al., 2016)(LiuSu et al., 2016)(Wang, et al., 2014)(Zhang, et al., 2005).

* Corresponding author: ziz.alya@gmail.com 
Li et al, (Li, Liwen et al., 2009) studied different knitting structure with silver coated conductive yarn to measure the confining pressure and electric resistance and in order to test the electric properties of conductive knitted fabric an electric model of 1X1 rib fabric was introduced. Guo and Berglin measured the resistance change and strain gauge properties of woven- knitted and coated textile based sensor(Guo \& Berglin, 2009). WhileEhrmann et al, study the electric resistance of polyester yarn containing a small amount of stainless steel wires to be used as a knitted breathing sensor (Ehrmann, et al., 2010)

Furthermore, the knitted loop structure was studied and a hexagonal model was developed to analyze the relationship between the electric resistance and load applied to the knitted conductive fabric in a unidirectional (Zhang, et al., 2005)as well as biaxial direction(Wang, et al., 2014). In order to compute the electric resistance of conductive knitting fabric, an empirical equation model was developed.

In 2011 Qureshi et al, studied different types of conductive yarns with four knitting structures (plain jersey, 1x1 rib, interlock and float) to design a knitting stretch sensorand interlock structure was selected for the sensor (Qureshi, et al., 2011), While Ehrmann et al, (Ehrmann, et al., 2010), examine the reliability of knitted elongation sensor developed form different conductive yarns, stitch size and knitting structure, results showed that full cardigan with medium size is better suited for use as stretching sensor. Another study was carried out in order to explore the effect of contact pressure of knitted strain sensor on the electric resistance. (Atalay, et al., 2013). In order to produce a knitted strain sensor a comparative study was conducted on the plain and interlock knitted structures using different conductive yarns, the successful strain sensor was realized in this study is the sensor with a series of single conductive courses within the interlock structure using Ag coated Nylon yarn(Atalay, et al., 2015).

Recently, the effect of float stitch(Liu , et al., 2016) andtuck stitch(Lui, Su et al., 2016) on the performance of electric functionof conductive knitted structure was studied.

This paper focuses on the study of the combination ratio of conductive yarn to nonconductive one with other knitting production parameters as well as the speed of contraction/ relaxation mechanism of fabric which could simulate breathing of human body at chest circumference. It can be a part of a cloth attached or applied on chest for monitoring breathing status.

\section{Materials and Methods}

\subsection{Materials:}

The conductive yarn used is Silver coated Polyamide (Nylon) Fiber (Ag/ Nylon); yarn count 70 denier ratio of silver to Nylon is $20 \%-80 \%$. The non-conductive yarn is nylon/ elastomeric yarn with yarn count 70 denier. The yarn has elasticity property which is highly recommended for producing the breathing sensor and nylon is well known with its high resilience 
and good durability. Furthermore, the yarn count is almost the same compared to Ag/ Nylon, so it can be easily calculates the ratio of the yarn in the samples produced.

\subsection{Method:}

All samples were produced on a flat knitting machine gauge 12and fabricated in single jersey structure with fixed number of course / piece (50). Table 1 shows the parameters levels used in this work.

Table 1 parameters carried out for the work

\begin{tabular}{|c|c|c|}
\hline Parameters & 1 & 2 \\
\hline - Stitch type & Normal & Float \\
\hline - No. of wales / piece & 180 & 360 \\
\hline $\begin{array}{l}\text { - Yarn combination ratio; } \mathrm{C}^{*} \text { : } \\
\mathrm{N}-\mathrm{C}^{* *} \text { yarn }\end{array}$ & $1: 3$ & $2: 2$ \\
\hline
\end{tabular}

* $\mathrm{C}$ : conductive yarn

* N-C yarn: non-conductive yarn

\section{- Dimensional measurement}

The width and length of the samples were measured, for each sample five measurements were taken and the values tabulated so as to estimate the mean value (see Table2).

Table 2the average width and length of the samples in (cm).

\begin{tabular}{|c|c|c|}
\hline $\begin{array}{c}\text { Sample } \\
\text { no. }\end{array}$ & $\begin{array}{c}\text { SL }^{*} \\
(\mathbf{c m})\end{array}$ & $\begin{array}{c}\mathbf{S W}^{*} \\
(\mathbf{c m})\end{array}$ \\
\hline $\mathbf{1}$ & 6.5 & 18.6 \\
\hline $\mathbf{2}$ & 9.3 & 8.0 \\
\hline $\mathbf{3}$ & 6.4 & 39.0 \\
\hline $\mathbf{4}$ & 10.3 & 15.2 \\
\hline $\mathbf{5}$ & 6.7 & 18.5 \\
\hline $\mathbf{6}$ & 10.8 & 7.4 \\
\hline $\mathbf{7}$ & 6.2 & 37.9 \\
\hline $\mathbf{8}$ & 10.1 & 15.1 \\
\hline
\end{tabular}

SL: Sample length - SW: Sample width

\section{- Electrical resistance measurement:}

In order to measure the electric resistance in the produced sensor knitted fabrics during the contraction/ relaxation mechanism; which simulates the human breathing, a cyclic tester was built (see Fig.1) which connected to a microcontroller to calculate the resistance. Two different breathing modes: sitting and walking were applied on the sensor knitted samples shown inTable 3 , the modes are varied in speed and time delay between cycles with 5\% stretching of the original length, 20 cycles were chosen to be close to the normal breathing rate for adults: $16-20$ per minute (Charbek \& Christensen, 2015). 


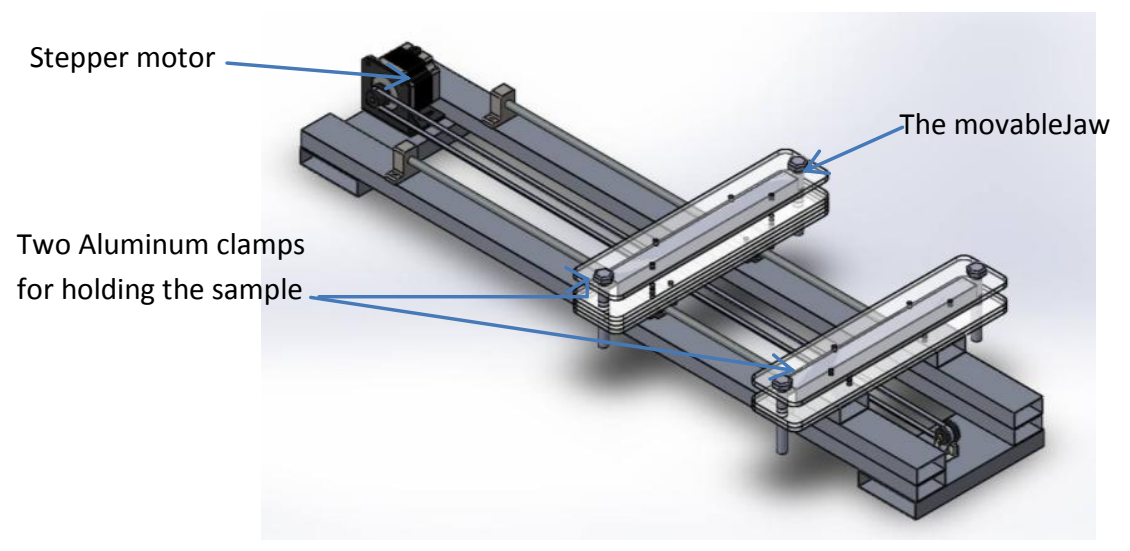

Figure 1 schematic design of cyclic tester

Table 3 different type of modes to simulate different breathing conditions

\begin{tabular}{|l|c|c|}
\hline \multicolumn{1}{|c|}{ Mode type } & $\begin{array}{c}\text { Speed } \\
\mathrm{mm} / \mathrm{sec}\end{array}$ & $\begin{array}{c}\text { Time delay } \\
\text { Sec. }\end{array}$ \\
\hline 1- Sitting & 12.5 & 0.7 \\
\hline 2- Walking & 15 & 0.4 \\
\hline
\end{tabular}

- Analysis of variance was carried out to define the main effect of the studied parameters on the resistivity and of the produced conductive samples as well as the difference of resistance along the cycles.

\section{Results and Discussion}

\subsection{Influence of studied parameters on the electric resistance:}

Samples specification and the results of the mean values of the electric resistance and $\Delta \mathrm{R}$ of sitting mode (SM) and walking mode (WM)are present in Table (4). The speed was varied to evaluate the performance of the knitting sensor; the results clear that the speed values are very close to each other as a result one speed (SM) was chosen to represent the charts for the study. Figure 2 show the graph plotted between resistance and time / second for the whole samples, from the Figure it can be seen that samples no.3, 4 and 7 has a reliable and uniform pattern with clear Hi/Lo peaks. The high peak in the graph represents the breath out as well as the relaxing state and the low peak shows the breath in. The high peak and the low peak together represent one cycle. When calculate the difference in resistance $(\Delta \mathrm{R})$, shown in table 4 . Sample no.3 shows the highest $\Delta \mathrm{R}$ values (1.02 and 1.1 $\Omega$ ) for SM and WM, respectively. While sample no. 4 and 7 recorded 0.3 and $0.7 \Omega$, respectively for both modes. For a breathing sensor performance it is preferable that the $\Delta \mathrm{R}$ is high so as to detect and monitor the breathing pattern easily (contraction and relaxation of a human chest) (Qureshi, et al., 2011). The rest of the samples have undesirable pattern and the range of the resistance value is unstable along the cycles as clear from Fig. 2. 
Table 4 samples specs., resistance and $\Delta R$ valuesof the 2 speed modes

\begin{tabular}{|c|c|c|c|c|c|c|c|}
\hline \multirow{2}{*}{$\begin{array}{c}\text { sample } \\
\text { no. }\end{array}$} & \multirow{2}{*}{ ST } & \multirow{2}{*}{$\mathbf{N W}$} & \multirow{2}{*}{$\mathbf{C R}$} & \multicolumn{2}{|c|}{ Sitting } & \multicolumn{2}{c|}{ walking } \\
\cline { 5 - 8 } & & & & $\mathrm{R} / \boldsymbol{\Omega}$ & $\Delta \mathrm{R} / \Omega$ & $\mathrm{R} / \Omega$ & $\Delta \mathrm{R} / \boldsymbol{\Omega}$ \\
\hline $\mathbf{1}$ & $\mathrm{N}$ & 180 & $1: 3$ & 5.76 & $\mathbf{0 . 6 0}$ & 5.99 & $\mathbf{0 . 7 2}$ \\
\hline $\mathbf{2}$ & $\mathrm{F}$ & 180 & $1: 3$ & 2.26 & $\mathbf{0 . 1 6}$ & 2.26 & $\mathbf{0 . 1 7}$ \\
\hline $\mathbf{3}$ & $\mathrm{N}$ & 360 & $1: 3$ & 7.79 & $\mathbf{1 . 0 2}$ & 7.91 & $\mathbf{1 . 1 0}$ \\
\hline $\mathbf{4}$ & $\mathrm{F}$ & 360 & $1: 3$ & 3.42 & $\mathbf{0 . 2 7}$ & 3.38 & $\mathbf{0 . 2 9}$ \\
\hline $\mathbf{5}$ & $\mathrm{N}$ & 180 & $2: 2$ & 2.49 & $\mathbf{0 . 3 7}$ & 2.43 & $\mathbf{0 . 3 4}$ \\
\hline $\mathbf{6}$ & $\mathrm{F}$ & 180 & $2: 2$ & 1.77 & $\mathbf{0 . 0 7}$ & 1.80 & $\mathbf{0 . 0 7}$ \\
\hline $\mathbf{7}$ & $\mathrm{N}$ & 360 & $2: 2$ & 3.75 & $\mathbf{0 . 6 7}$ & 3.76 & $\mathbf{0 . 6 8}$ \\
\hline $\mathbf{8}$ & $\mathrm{F}$ & 360 & $2: 2$ & 1.86 & $\mathbf{0 . 1 1}$ & 1.84 & $\mathbf{0 . 1 0}$
\end{tabular}

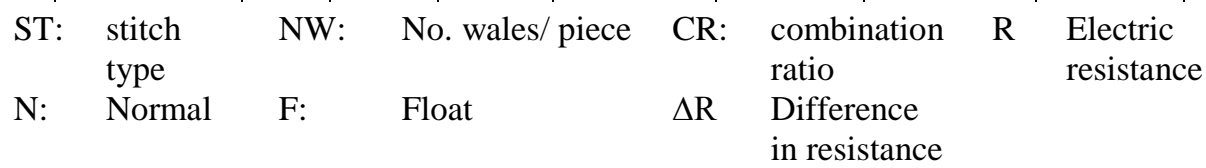
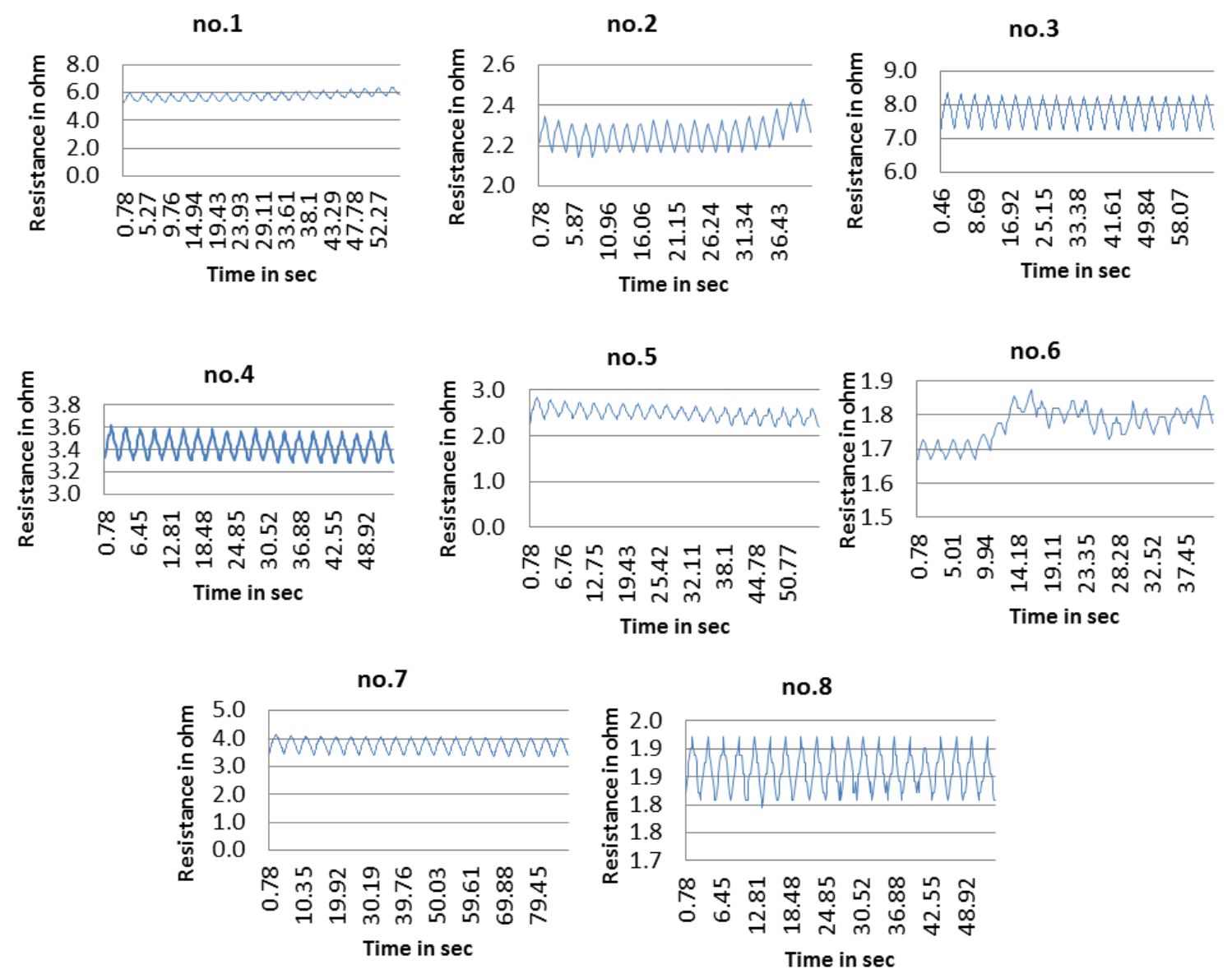

Figure 2Relationship between resistance and time (in seconds) for the whole samples in the setting mode

The effect ofdifferent parameters on the electric resistance are shown in Figures 3 and 4, the Figures present the relationship between resistance and stretching,the knitted sensor fabric for samples with NW (no. of wales) 180 and 360, respectively. Figure 3 shows samples of 
$\mathrm{NW}=180$,it can be seen that there are 2 bars of normal single jersey (NSJ)differentin combination ratio (CR) 1:3 and 2:2 respectively, the sample of CR 1:3 show high resistance value (5.76 $\Omega$ ) than the ones of CR 2:2 (2.49 $\Omega$ )while, the 2 bars of float single jersey (FSJ)different inCR 1:3 and 2:2 respectively.Thesample of CR 1:3 showslightly higher resistance value (2.26 $\Omega$ ) than the sample with CR 2:2 (1.7 $\Omega$ ), when comparing it with the NSJ both gives low resistance.

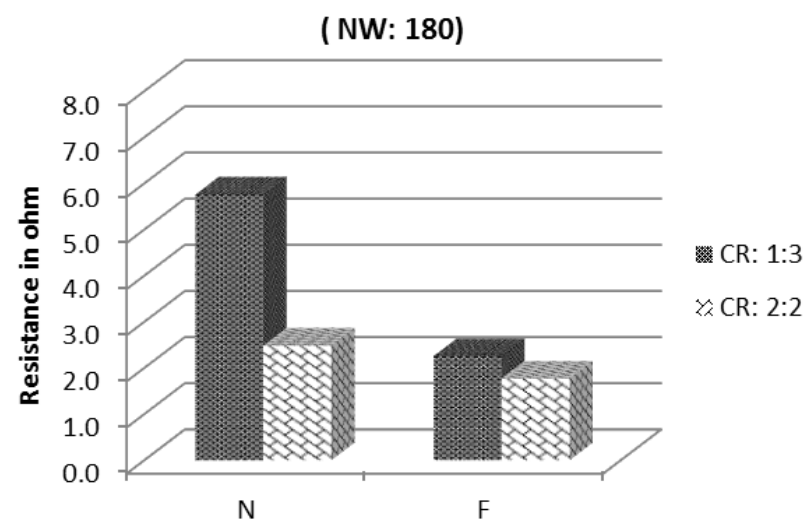

Figure 3 Relationship between resistance and 5\% stretching of SJ fabric in 20cycles for samples of NW is 180 of $\mathbf{N}$ and $\mathbf{F}$ stitch and different $\mathbf{C R}$.

Figure 4represent samples of $\mathrm{NW}=360$, it can be noticed that there are 2 bars for SJN samples differentin CR 1:3 and 2:2 respectively, the sample of CR 1:3 is higher in resistance (7.79 $\Omega$ ) than the CR 2:2 (3.75 $\Omega$ )on the other hand, the 2 bars of FSJaredifferent inCR 1:3 and 2:2, respectively. The sample of CR 1:3 show higher resistance value (3.42 $\Omega$ ) than the sample with CR 2:2 (1.86 $\Omega$ ), when comparing with the SJN both gives low resistance values. From the previous charts, it can be seen that even though samples of $\mathrm{NW}=360$ show higher resistance value compared with samples of NW=180, the ANOVA results indicated insignificant ( $\mathrm{P}$ value is 0.2 ) for SM and WM. Furthermore,the results of the analysis of variance for SM and WM,indicates that there is a significant effect on the resistance when changing the ST (P value is 0.024 and 0.034 ) and $\mathrm{CR}$ (P value is 0.027 and 0.037 ) SM and WM, respectively.

(NW: 360)

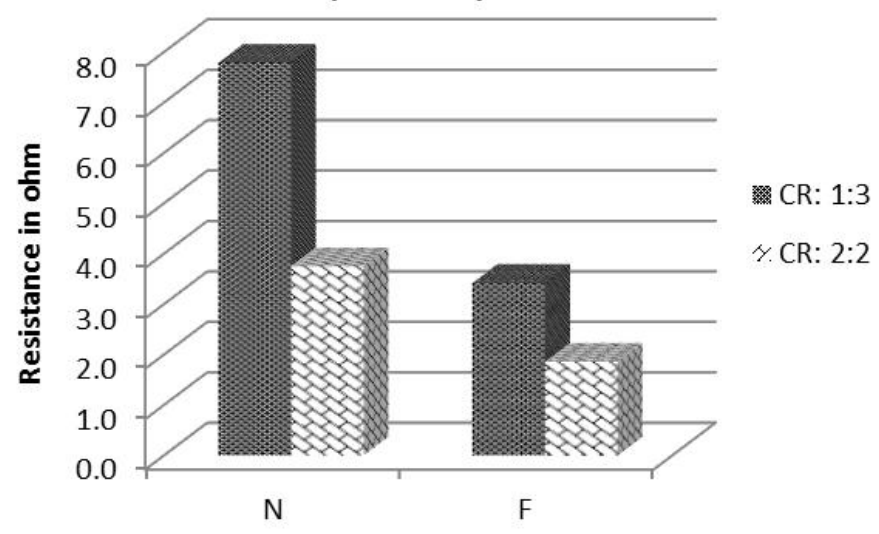

Figure 4 Relationship between resistance and 5\% stretching of SJ fabric in 20cycles for samples of NW is 360 of $\mathbf{N}$ and $\mathbf{F}$ stitch and different $\mathbf{C R}$. 


\subsection{Influence of studied parameters on the resistance difference $(\Delta R)$ :}

Figure 5 and 6 presents the effect of the different parameters on $\Delta \boldsymbol{R}$. The Figures show the relationship between the $\Delta \boldsymbol{R}$ and stretching of knitted sensor samples with NW (no. of wales) 180 and 360, respectively.

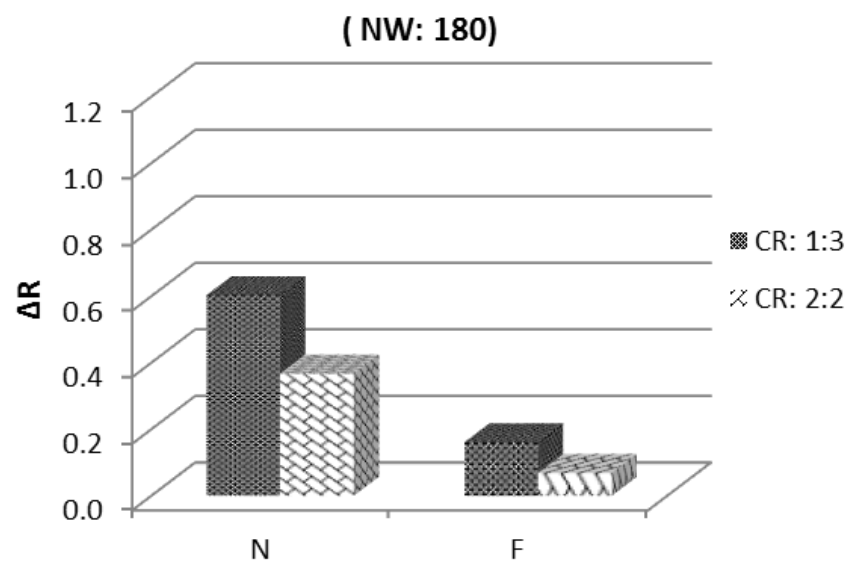

Figure 5 Relationship between $\Delta R$ and $5 \%$ stretching of SJ fabric in 20cycles for samples of NW is 180 of $N$ and $F$ stitch and different $C R$.

Figure 5 shows samples of NW=180, from the Fig. there are 2 bars of normal single jersey (NSJ) different in CR 1:3 and 2:2, respectively, it can be noticed that sample of CR 1:3 is higher in $\Delta \mathrm{R}$ $(0.60 \Omega)$ than the ones of CR 2:2 (0.37 $\Omega)$ on the other hand, the 2 bars of float single jersey (FSJ) different in CR 1:3 and 2:2, respectively.Sample of CR 1:3 has slightly higher $\Delta R(0.16 \Omega)$ than

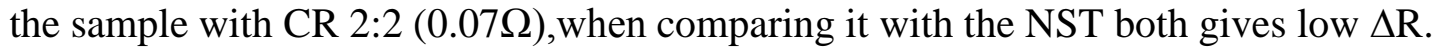

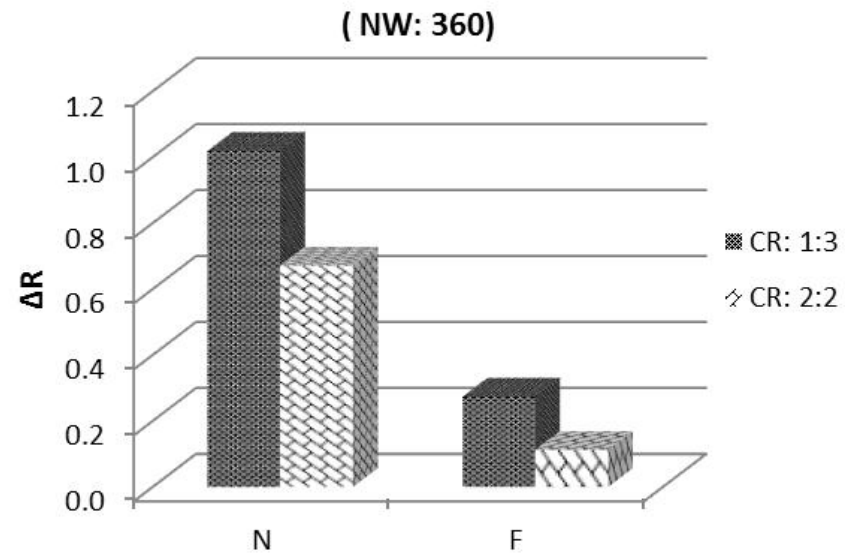

Figure 6 Relationship between $\Delta R$ and $5 \%$ stretching of SJ fabric in 20 cycles for samples of $\mathbf{N W}$ is 360 of $N$ and $\mathbf{F}$ stitch and different $\mathbf{C R}$.

Figure 6 shows samples of NW=360 from the Fig. there are 2 bars of NSJ different in CR 1:3 and 2:2 respectively, it can be noticed that sample of CR 1:3 has higher value in $\Delta \mathrm{R}(1.02 \Omega)$ than CR 2:2 $(0.67 \Omega)$ on the other hand, the 2 bars of FSJdifferent in CR 1:3 and 2:2, respectively. Sample of CR 1:3 show higher $\Delta \mathrm{R}(0.27 \Omega)$ than sample with $\mathrm{CR} 2: 2(0.11 \Omega)$ but both gives low $\Delta \mathrm{R}$ 
when compared with the SJN. From the previous charts, it can be observed that samples of $N W=360$ show higher $\Delta R$ compared with samples of $N W=180$, and samples with less number of conductive yarns shows increase in $\Delta \mathrm{R}$. Moreover, The results conducted from the variance of analysis shows highly significant in ST $(\mathrm{P}=0.004,0.005)$ in sitting and walking modes respectively while it shows significant effect on the other two parameters NW and $\mathrm{CR}(\mathrm{P}=0.065$, $0.089)$ and $(\mathrm{P}=0.073,0.049)$ in sitting and walking modes respectively.

\section{Conclusion}

- The performance of the electric resistance was studied and it was found that there is a significant effect for ST and CR, while the width of the sample doesn't show a significant effect on the resistance value.

- Normal stitch shows high resistance values than the float one.

- The accuracy of the discrimination of breathing cycle improved by the increase in the $\Delta \mathrm{R}$.

- The $\Delta \mathrm{R}$ is highly affected by the change of ST and also shows influence by the change in NW and CR.

- The increase in NW show increase in $\Delta \mathrm{R}$.

- The speedvariation shows no effect on the electric resistance and $\Delta \mathrm{R}$ values.

- The results showed that SJ knit fabric with less number of conductive yarns and high NW can be applied as a breathing sensor.

- The authors suggest further investigation to be applied on other knit structures such as Rib and interlock in order to examine its reliability as a breathing sensor.

\section{References}

Atalay, O, W R Kennon, and M D Husain. "Textile based weft knitted strain sensors: Effect of fabric parameters on sensor properties." Sensors,pp. 11114-11127 (2013).

Atalay, O, A Tuncay, M D Husain, and W R Kennon. "compartive study of the weft knitted strain sensor." journal of industrial textiles, pp. 1-29 (2015).

Ceken, F, G Pamuk, O Kayacan, A Ozkurt, and S S Ugurlu. "Electromagnetic shielding properties of plian knitted fabric containing conductive yarns." Journal of engineered fibers and fabrics, pp. 81-87 (2012).

Charbek, E, and B Christensen. "Normal Vital Signs." Medscape. http://emedicine.medscape.com/article/2172054-overview.(2015).

Cheng, K B, T H Ueng, and G Dixon. "electrostatic discharge properties of stainless steel/polyester woven fabrics." Textile research journal, pp. $732-738$ ( 2001).

Coyle, S, E Mitchell, T E Ward, G May, N E O'Connor, and D Diamond. "Textile sensors for personalized feedback." IAPMA congress. Milton Keynes, UK: ECIR2010 workshop on information access for personal media archives, (2010). 
Ehrmann, A., F Heimlich, A. Brucken, M O Weber, and R Haug. "knitted breathing sensor." knitting, pp. 222-223 (2010).

Guo, L, L Berglin, U Wiklund, and H Mattila. "Design of a garment-based sensing system for breathing monitoring." Textile research journal, pp.499-509 (2013).

Guo, Li, and L Berglin. "Test and evaluation of textile based stretch sensor." World textile conference. Turkey: AUTEX, (2009).

Li, L, S Liu, F Ding, T Hua, W M Au, and K S Wong. "Electromechanical analysis of lengthrelated resistance and contact resistance of conductive knitted fabrics." Textile research journal, pp. 2062-2070 (2012).

Li, L, W M Au, Y Li, K M Wan, W Y chung, and K S Wong. "A Novel Design Method for an Intelligent Clothing Based on Garment Design and Knitting." Textile Research Journal 79, no. 18, pp. 1670-1679 (2009).

Li, Li, Wai M Au, Kam M Wan, Sai Ho Wan, Wai Yee Chung, and K S Wong. "A resistive network model for conductive knitting stitches." Textile research journal, pp. 935947(2010).

Li, Liwen, Kun Yang, G Song, L Zhang, and Juan Guo. "Research and application of the property of conductive knitted fabrics." Modern appplied science, pp. 84-88 (2009).

Liu , S, C Yang, Y Zhao, Xian M Tao, Ji Tong, and L Li. "The impact of float stitches on the resistance of conductive knitted structures." Textile research journal, pp. 1-19 (2016).

Liu, Su, J Tong, C Yang, and Li Li. "Smart E-textile: Resistance properties of conductive knitted fabric - Single pique." Textile research journal, pp. 1-16(2016).

Merrit, C R. "electronic textile-based sensors and systems for long term health monitoring." Ph.D. Dissertation, North Carolina State university, Raleigh, (2008).

Meyer, J, B Arnrich, J Schumm, and G Troster. "Design and Modeling of a Textile Pressure Sensor for Sitting Posture Classification." IEEE, pp.1391-1398 (2010).

Noury, N, et al. "VTAMN--a smart clothe for ambulatory remote monitoring of physiological parameters and activity." Enterprise Networking and Computing in Healthcare Industry,. IEEE,pp. 155 - 160 (2004).

Paradiso, R, G Loriga, and N Taccini. "A wearable health care system based on knitted integrated sensors." IEEE Transactions on Information Technology in Biomedicine, pp. 337 - 344 (2005). 
Perumalraj, R, and K S Narayanan. "Nano silver conductive composite material for electromagnetic compatibility." journal of reinforced plastics and composites, pp.10001016 (2014).

Pinar, Anna, and L Michalak. "influence of structural parameters of wale-knitted fabrics on thier electrostatic properties." Fibers and textile in Eastern Europe, pp. 69-74(2006).

Qureshi, W, Li Guo, J peterson, L Berglin, A K Mehrjerdi, and M Skrifvars. "Knitted wearablestretch sensor for breathing monitoring application." Proc Ambience, pp.7276(2011).

Rothmaier, M, M P Luong, and F Clemens. "Textile pressure sensor made of flexible plastic optical fibers." Sensors,pp. 4315-4329 (2008).

Wang, J, H Long, S Soltanian, P Servati, and F Ko. "Electromechanical properties of knitted wearable sensors: part 1 - theory." Textile Research Journal, pp. 3-15 (2014).

Yang, C M, W T Huang, T L Yang, M C Hsieh, and C T Liu. "Textiles digital sensors for detecting breathing frequency." 5th International Workshop on Wearable and Implantable Body Sensor Networks. China: IEEE, pp.276-279 (2008).

ZHANG, H, X TAO, S WANG, and T YU. "Electro-Mechanical Properties of Knitted Fabric Made From Conductive Multi-Filament Yarn Under Unidirectional Extension." TEXTILE RESEARCH JOURNAL, pp. 598-606(2005).

Zięba, J, and M Frydrysiak. "Textronics - Electrical and Electronic Textiles. Sensors for Breathing Frequency Measurement." Fibers \& textiles in Eastern Europe, pp. 43-48 (2006).

$$
\begin{aligned}
& \text { الملخص باللغة العربية } \\
& \text { ملائمة قماش التريكو الموصل للكهرباء لأستشعار تنفس الأنسان } \\
& \text { علياء عبد العزيز محمد ــ محمد عزبقحمد2 - زينب محمد عبد المجيد2 ــ احمد سعيد3 } \\
& \text { 1 جامعة عين شمس-كليه البنات_قسم الأقتصاد المنزلى (ملابس ونسيج) }
\end{aligned}
$$

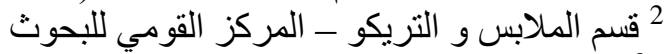

$$
\begin{aligned}
& 3 \text { هندسة إلكترونيات و اتصالات - جامعة حلو ان الن }
\end{aligned}
$$


هذا البحث يقوم بجر است مدى ملاءمة قماش التريكو المصنوع من خيوطموصلةتلكهرباء من أجل إنتاجقماش ميستشعر التنفس

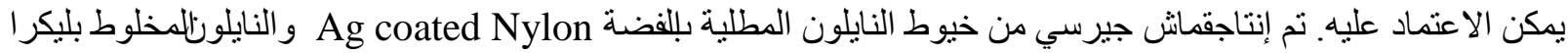
Nylon/Elastomeric الخيوط غير الموصلة(CR) و عدد الصفوف في العينة (NW) (عرض العينة)). تم تصميم جهاز (cyclic tester)لمحاكاة آلية

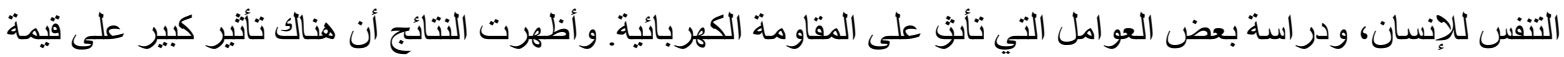

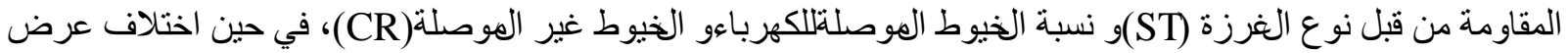

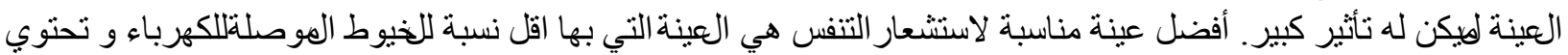
علي الغرزة العادية و التئيا عدد اكبر من الصفوف. 